Article

\title{
Suicide and Health Crisis in Extremadura: Impact of Confinement during COVID-19
}

\author{
Ismael Puig-Amores*(D), Isabel Cuadrado-Gordillo (D) and Guadalupe Martín-Mora Parra \\ Department of Psychology and Anthropology, University of Extremadura, 06071 Badajoz, Spain; \\ cuadrado@unex.es (I.C.-G.); guadammp@gmail.com (G.M.-M.P.) \\ * Correspondence: ipuigamores@unex.es
}

check for

updates

Citation: Puig-Amores, I.;

Cuadrado-Gordillo, I.; Parra, G.M.-M. Suicide and Health Crisis in

Extremadura: Impact of Confinement during COVID-19. Trauma Care 2021, 1, 38-48. https://doi.org/10.3390/ traumacare1010004

Received: 27 March 2021

Accepted: 28 April 2021

Published: 4 May 2021

Publisher's Note: MDPI stays neutral with regard to jurisdictional claims in published maps and institutional affiliations.

Copyright: (c) 2021 by the authors. Licensee MDPI, Basel, Switzerland. This article is an open access article distributed under the terms and conditions of the Creative Commons Attribution (CC BY) license (https:// creativecommons.org/licenses/by/ $4.0 /)$.

\begin{abstract}
Because of its impact on social well-being, mental health, and financial security, the COVID19 health crisis may increase the risk of suicide. This study's objective was to determine what impact the period of confinement might have had on the incidence of deaths by suicide (DBS) in the Extremadura region (Spain). Cases registered in the Institutes of Legal Medicine and Forensic Science (IMLyCFs) from January 2015 to December 2020 were collected. Intra- and interannual comparisons were made of the suicide rates in the periods of confinement (March-June) and postconfinement (July-October) of 2020 with those of the preceding 5 years. After seasonally adjusting the data by means of a time series analysis, rate ratios (RRs) were calculated together with their $95 \%$ confidence intervals (CI). There were no significant differences between the suicide rates of 2020 and the mean of the preceding 5 years ( $R R=0.94 ; C I: 0.56-1.55)$, and neither did any differences seen in the intraannual analysis from the period of confinement to postconfinement reach statistical significance $(R R=0.74 ; C I: 0.45-1.20)$. It is necessary to strengthen vigilance during and after the crisis and ensure that assistance mechanisms are in place to prevent an increase in suicides.
\end{abstract}

Keywords: suicide; lockdown; COVID-19

\section{Introduction}

People's health and quality of life are strongly influenced by social, political, economic, environmental, and cultural contexts [1]. In this sense, the current health crisis deriving from COVID-19 is a life event that seems to be impacting people's mental health negatively [2-8], and there are fears that it could increase the risk of DBS, as has been the case in other crises [4-8], due to its destructive direct or indirect repercussions on social well-being, mental health, housing, work, and financial security. Some studies, however, have shown that suicide rates may decrease during or immediately after a crisis, with the risk varying from one group of people to another due to, among other aspects, cultural, religious, genetic, and socioeconomic factors [5]. Indeed, in general terms, there seems to be no clear trend in DBS after, for example, a natural disaster [9].

\subsection{Previous Crises}

As an example of the consequences deriving from a global crisis, the mortality data of 27 European countries in the period of the economic recession of 2008 [10] showed an increase in DBS in men in the first postcrisis year (2009) compared with the eight precrisis years of 2000-2007 (RR = 1.042; CI: 1.035-1.081), while in women, it remained stable $(\mathrm{RR}=1.003$; CI: 0.995-1.010).

In Spain during the same crisis, pre-to-post comparison (2006-2007 vs. 2011-2012) showed an increase in the prevalence of mental health problems among men ( $R R=1.15$; CI: 1.04-1.26), while in women, there was a slight decrease ( $R R=0.92, C I: 0.87-0.98)$ [4]. In the same context, the rate of suicide attempts increased for both sexes during the 5 years after the onset of the crisis (2008-2012) compared with the precrisis period (2003-2007) [11], 
and the rate of completed suicides underwent an overall $8 \%$ increase during the period $2005-2010$, being greater in men $(R R=1.10 ; C I$ : $1.026-1.179)$ than in women $(R R=1.013$; CI: 0.894-1.149) [12].

\subsection{Background to the COVID-19 Health Crisis}

With respect to the health consequences expected during a health crisis, the immediate antecedent was the 2003 Severe Acute Respiratory Syndrome (SARS) epidemic in which some biopsychosocial risk factors for suicide, such as loneliness, social disconnection, limited access to medical care, and stress induced by the fear of suffering from those factors, were associated with an exceptionally high rate of DBS in persons older than 65, passing from 28.44 per 100,000 inhabitants in 2002 to values in the range from 37.46 to 40.35 depending on the different studies [13-15]. Specifically, social disconnection and loneliness, especially in the elderly, could generate or enhance depressive symptoms [16] and suicidal behaviors [17-22].

\subsection{COVID-19 Crisis}

In Spain, when the World Health Organization declared the emergency situation caused by the epidemic outbreak of COVID-19 [23] to be an international pandemic, the country's government adopted the first urgent measures to confront the disease's spread and its economic impact [24]. Some days later, on 14 March 2020, it declared a state of alarm to manage the health crisis situation over the whole of the national territory. Confinement was the first measure adopted. This included the "limitation of persons" freedom of movement," which meant that the entire Spanish population remained confined to their homes during the time the state of alarm was in force [25]. These extraordinary measures underwent six continuous extensions until 00:00 h 21 June [26].

These restrictions on everyday life generated a series of stressors capable of directly affecting people's health [2,3,27-29]. The duration of the confinement, the lack of information, the fear of getting ill or infecting others, the frustration caused by being unable to carry out daily activities such as leaving the house, the loss of freedom, the separation from one's environment, and uncertainty were some of the psychosocial stressors associated with the health crisis situation that were potential generators of negative psychological effects during the pandemic [30], effects that could be risk factors for suicidal behavior [4-8,31].

Early studies during the first months of the pandemic found no significant increase in DBS. Indeed, while some indicated absence of significant differences in any direction [32-34], others found a decrease in suicides during confinement in the first months of the pandemic [35-40].

In Massachusetts (USA), no significant differences were observed in the DBS incidence rate registered from March to May 2020 compared with 2019 (RR = 0.94; CI: 0.76-1.15) [32], neither were any significant differences found for Queensland (Australia) when comparing DBS rates for the period from February to August 2020 with the same period from 2015 to 2019 (RR = 0.94; CI: 0.82-1.06) [33].

However, in Austria, a significant decrease in DBS was observed in the first 6 months of the response to the pandemic (from April to September of 2020) when compared with the mean of the years 2006 to 2019 (chi-squared $=4.553, \mathrm{df}=1, p=0.033$ ), although the comparison by trimesters only showed significance for that from July to September (chisquared $=4.21, \mathrm{df}=1 p=0.040$ ) [39]. In Leipzig (Germany), there was an intra-annual reduction in DBS registered between the confinement and nonconfinement months of 2020, although no significant differences were found when the comparison was with the years 2015-2019 ( $R R=1.084 ; C I$ : 0.665-1.766) [34]. In the same line, research in Japan [35] found a $14 \%$ decline during the months of February to June ( $R R=0.86$; CI: $0.82-0.90)$ and a $16 \%$ increase during the months of July to October ( $R R=1.16$; CI: 1.11-1.21) relative to the preceding 5 years, although another study in Japan, which compared the period from March to June 2020 with the same period of the preceding 10 years [36], did not find any significant differences, but it did find an overall decrease in cases. Norway [37] and 
Korea [38] have published DBS statistics for the first months of the pandemic. They both indicate a reduction in DBS compared with previous years, although neither publication included any statistical analysis as to whether the differences were significant.

\subsection{Justification for the Study}

This work was carried out in the Extremadura region (Spain), which has a censused population of 1,063,565 inhabitants and whose annual rate of DBS has remained fairly stable over the preceding 5 years. Specifically, 2020 showed a slight increase of 3.70\% compared with 2019 in particular and of $4.60 \%$ compared with the mean of the preceding 5 years (2015-2019). In Spain, apart from overall figures, there are no official data available and no studies that the authors are aware of analyzing the variation in DBS rates in the months of confinement and postconfinement during the COVID-19 crisis. The objective of this study was therefore to determine to what extent and in which sense the period of confinement that was decreed during the state of alarm may have affected the incidence of DBS in the Extremadura region.

\section{Materials and Methods}

\subsection{Data Acquisition}

The data were extracted from the DBS files of the provincial IMLyCFs of Cáceres and Badajoz (the two provinces conforming to the Extremadura region), with the approval of the Teaching Commission of these centers and the authorization of Spain's Ministry of Justice, both subject to Organic Law 3/2018 of December 5 on the Protection of Personal Data and the Guarantee of Digital Rights.

The records for 2015-2020 were reviewed, and the DBS that occurred from January to December of each year were collected. To calculate the incidence rates, the population counts used were those published on January 1 of each year [41], except for 2020, which had not yet been published at the date of the study. This last population was estimated by applying to 2019 the flux of vegetative growth and migratory balance during that year $[42,43]$. The mean suicide rate for 2015-2019 was calculated from the mean population for those years. In all populations, the under-15 age group was excluded because it was not considered a population at risk of suicide given its minimal or null recorded incidence.

\subsection{Study Design}

This was an observational and retrospective study in which the SARS-CoV-2 exposed and unexposed groups are defined differently in accordance with whether the analysis is inter- or intra-annual, as will be detailed below.

Prior to the rate analysis, using the statistical software package SPSS.21 (IBM Corp. Armonk, NY, USA), the raw data series were deseasonalized by means of a time series analysis with no prediction. After this seasonal decomposition, the cases that occurred from March to October of each year were selected for analysis. The deseasonalized rates were calculated by dividing the number of cases left after removing the seasonal component by each year's total population.

The same statistical software was used to perform all the comparisons. Contingency tables were calculated, yielding the values of RR with the corresponding 95\% confidence interval. This method was decided on because it provides a straightforward estimate of the percentage variation between two incidence rates. A further reason was that it allows the results to be compared with those of reference studies, which used the same method to determine the index of variation. In the present study, the resulting value is equivalent to how much more likely DBS is in the group of people exposed to confinement (year 2020) relative to the unexposed group (years 2015-2019). The calculations were made starting from a contingency table, applying the following equation:

$$
\mathrm{RR}=\frac{\frac{\text { exposed cases }}{\text { exposed population }}}{\frac{\text { unexposed cases }}{\text { unexposed population }}}=\frac{\text { exposed incident rate }}{\text { unexposed incident rate }}
$$


With this method, a value of RR $>1$ would indicate that DBS had increased, and this increase would be significant if the lower limit of the CI was above 1 . A value of $R R<1$ would indicate that DBS had decreased, and this would be significant if the upper limit of CI was below 1 .

Procedure

After the seasonal decomposition, the first analysis was to compare the 2020 DBS with the mean of the preceding 5 years in each of the months studied to check for variations between the two periods. An interannual comparison was then made to analyze the variation in the DBS incidence observed in the total period of confinement (March-June 2020) vs. the incidence in the same period of each of the preceding 5 years (2015-2019) and the mean of those years, considering for the exposed and unexposed groups the total population of Extremadura for the year 2020 and for 2015-2019, respectively (Table 1).

Table 1. The interannual analysis (confinement).

Exposed (Mar-Jun 2020)

Suicides (Cases)

Total Population
Unexposed (Mar-Jun 2015-2019)

Suicides (Cases)

Total Population

The same procedure was followed to analyze the first four months of postconfinement (July-October) (Table 2).

Table 2. The interannual analysis (postconfinement).

\begin{tabular}{cc}
\hline Exposed (Jul-Oct 2020) & Unexposed (Jul-Oct 2015-2019) \\
Suicides (Cases) & Suicides (Cases) \\
Total Population & Total Population \\
\hline
\end{tabular}

Finally, to check whether there was an intra-annual increase in DBS postconfinement, a comparison was made for each year between the DBS observed from March to June (exposed cases) versus the DBS observed from July to October (unexposed cases) (Table 3).

Table 3. The intra-annual analysis (confinement vs. postconfinement).

\begin{tabular}{cc}
\hline Exposed (Mar-Jun 2015-2020) & Unexposed (Jul-Oct 2015-2020) \\
Suicides (Cases) & Suicides (Cases) \\
Total Population & Total Population \\
\hline
\end{tabular}

\section{Results}

\subsection{Analysis of DBS in the Total Period}

Table 4 lists the DBS cases and raw risk ratios registered in the months and years of the study. The last column gives the results for the contrast between each month of the year 2020 (exposed) and the corresponding mean of the preceding 5 years (unexposed). Figure 1 shows the trends of the RR of the original and of the seasonally adjusted series. 
Table 4. Suicide cases and risk ratios in Extremadura in the period March-October 2015-2020 (original series and seasonally adjusted series).

\begin{tabular}{|c|c|c|c|c|c|c|c|c|}
\hline \multirow{3}{*}{ Month } & \multicolumn{7}{|c|}{ Year } & \multirow{3}{*}{$\mathrm{RR}(\mathrm{CI}=95 \%)$} \\
\hline & \multicolumn{7}{|c|}{ Population } & \\
\hline & 939,582 & 936,220 & 930,789 & 925,626 & 923,065 & 931,056 & 919,761 & \\
\hline \multicolumn{9}{|c|}{ Cases and Risk Ratios of the Original Series } \\
\hline Mar & $4(0.43)$ & $13(1.39)$ & $6(0.64)$ & $11(1.19)$ & $6(0.65)$ & $8(0.86)$ & $7(0.76)$ & $0.89(0.32-2.44)$ \\
\hline Apr & $8(0.85)$ & $11(1.17)$ & $6(0.64)$ & $7(0.76)$ & $12(1.30)$ & $8.8(0.95)$ & $10(1.09)$ & $1.12(0.46-2.77)$ \\
\hline May & $10(1.06)$ & $11(1.17)$ & $9(0.97)$ & $7(0.76)$ & $10(1.08)$ & $9.4(1.01)$ & $9(0.98)$ & $1.01(0.40-2.55)$ \\
\hline Jun & $7(0.75)$ & $7(0.75)$ & $11(1.18)$ & $5(0.54)$ & $5(0.54)$ & $7(0.75)$ & $5(0.54)$ & $0.72(0.23-2.28)$ \\
\hline Jul & $8(0.85)$ & $9(0.96)$ & $7(0.75)$ & $9(0.97)$ & $16(1.73)$ & $9.8(1.05)$ & $11(1.2)$ & $1.11(0.47-6.62)$ \\
\hline Aug & $3(0.32)$ & $9(0.96)$ & $11(1.18)$ & $5(0.54)$ & $9(0.98)$ & $7.4(0.79)$ & $13(1.41)$ & $1.88(0.75-4.71)$ \\
\hline Sep & $5(0.53)$ & $10(1.07)$ & $9(0.97)$ & $6(0.65)$ & $7(0.76)$ & $7.4(0.79)$ & $8(0.87)$ & $1.16(0.42-3.19)$ \\
\hline Oct & $2(0.21)$ & $3(0.32)$ & 10 (1.07) & $8(0.86)$ & $4(0.43)$ & $5.4(0.58)$ & $7(0.76)$ & $1.42(0.45-4.47)$ \\
\hline \multicolumn{9}{|c|}{ Cases and Risk Ratios of the Seasonally Adjusted Series } \\
\hline Mar & $3(0.32)$ & $12(1.28)$ & $5(0.54)$ & $10(1.08)$ & $5(0.54)$ & $7(0.75)$ & $6(0.65)$ & $0.87(0.29-2.58)$ \\
\hline Apr & $6(0.68)$ & $9(1.01)$ & $4(0.48)$ & $5(0.59)$ & $10(1.13)$ & $7(0.75)$ & $8(0.92)$ & $1.16(0.42-3.19)$ \\
\hline May & $8(0.90)$ & $9(1.01)$ & $7(0.80)$ & $5(0.59)$ & $8(0.92)$ & $8(0.86)$ & $7(0.81)$ & $0.89(0.32-2.44)$ \\
\hline Jun & $8(0.86)$ & $8(0.86)$ & $12(1.29)$ & $6(0.65)$ & $6(0.65)$ & $8(0.86)$ & $6(0.66)$ & $0.76(0.26-2.19)$ \\
\hline Jul & $5(0.59)$ & $6(0.70)$ & $4(0.49)$ & $6(0.71)$ & 13 (1.47) & $7(0.75)$ & $8(0.93)$ & $1.16(0.42-3.19)$ \\
\hline Aug & $3(0.31)$ & $9(0.95)$ & $11(1.17)$ & $5(0.53)$ & $9(0.96)$ & $7(0.75)$ & $13(1.40)$ & $1.88(0.75-7.71)$ \\
\hline Sep & $5(0.53)$ & $10(1.06)$ & $9(0.96)$ & $6(0.64)$ & $7(0.75)$ & $7(0.75)$ & $8(0.86)$ & $1.16(0.42-3.19)$ \\
\hline Oct & $4(0.42)$ & $5(0.53)$ & $12(1.29)$ & $10(1.08)$ & $6(0.65)$ & $7(0.75)$ & $9(0.98)$ & $1.30(0.48-3.49)$ \\
\hline
\end{tabular}

Note: RR is the risk ratio comparing the DBS of the year 2020 with the corresponding mean DBS of the preceding 5 years.

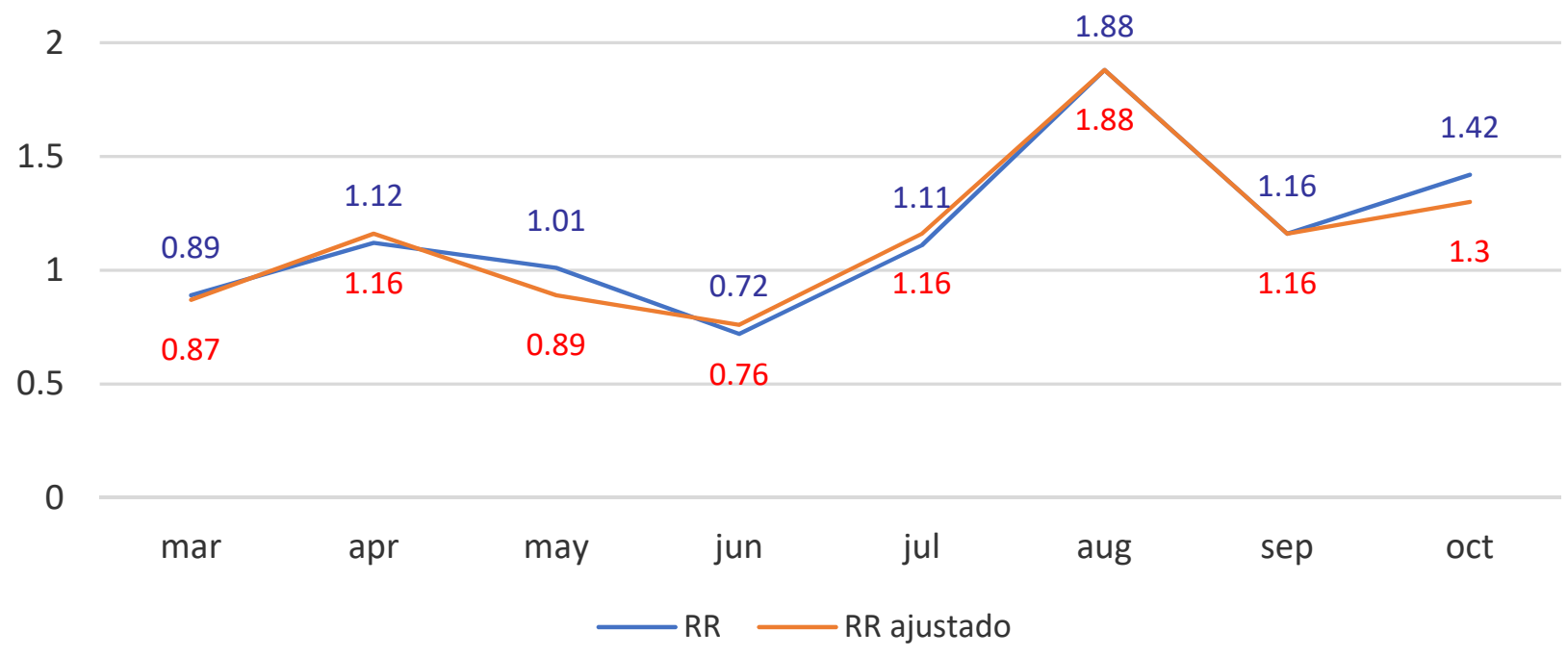

Figure 1. Trends of the RR (original vs. seasonally adjusted series).

This first analysis does not provide any strong evidence for change in the likelihood of suicidal acts in the exposed population whether during the confinement or in the months postconfinement. This is so both with the deseasonalized series and the original unadjusted series.

As one observes in both parts of the table, there were no significant differences in DBS incidence in any of the months of 2020 analyzed compared with the corresponding mean of the preceding 5 years. Likewise, comparing the monthly rates for 2020 with those of the preceding years, one observes that all the confidence intervals include the value 1. 


\subsection{Analysis of DBS in the Confinement Period}

This second analysis did not provide any significant results suggestive of a greater likelihood of committing a suicidal act in the population exposed to confinement than in the unexposed population.

The comparison of the total DBS that occurred during the 2020 confinement period with each of the preceding 5 years revealed no significant differences, finding that the recorded rates and the calculated RRs were fairly stable over the course of the series (Table 5). The comparison of 2020 with the mean of 2015-2019 did not show any statistically significant difference ( $R R=0.94 ; C I: 0.56-1.58)$.

Table 5. Total DBS (seasonally adjusted) in the confinement period months (March-June).

\begin{tabular}{cccccccc}
\hline Year & $\mathbf{2 0 1 5}$ & $\mathbf{2 0 1 6}$ & $\mathbf{2 0 1 7}$ & $\mathbf{2 0 1 8}$ & $\mathbf{2 0 1 9}$ & $\mathbf{2 0 1 5 - 2 0 1 9}$ & $\mathbf{2 0 2 0}$ \\
\hline Seasonally adjusted cases & 26 & 39 & 29 & 27 & 30 & 30 & 28 \\
Seasonally adjusted rates & 2.76 & 4.16 & 3.11 & 2.91 & 3.25 & 3.24 & 3.04 \\
RR & 1.1 & 0.73 & 0.98 & 1.04 & 0.94 & 0.94 & 1 \\
CI (95\%) & $(0.65-1.88)$ & $(0.45-1.19)$ & $(0.58-1.64)$ & $(0.62-1.77)$ & $(0.56-1.57)$ & $(0.56-1.58)$ & \\
\hline
\end{tabular}

Note: RR is the risk ratio comparing the DBS of the four months of the year 2020 with those of each of the preceding 5 years and with the mean of those years.

\subsection{Analysis of DBS in the Postconfinement Period}

The results of this third analysis (Table 6) showed the highest DBS rate to correspond to the year 2020, although the variation with respect to the mean of the preceding 5 years was not significant. Nonetheless, in the comparisons with each of those 5 years separately, a significant difference was found with the year 2015 ( $R R=2.28$; CI: 1.29-4.05). As can be seen in the table, the 2015 rate was the lowest of the series, with 17 cases as against the 38 of 2020 .

Table 6. Total DBS (seasonally adjusted) in the postconfinement period months (July-October).

\begin{tabular}{cccccccc}
\hline Year & $\mathbf{2 0 1 5}$ & $\mathbf{2 0 1 6}$ & $\mathbf{2 0 1 7}$ & $\mathbf{2 0 1 8}$ & $\mathbf{2 0 1 9}$ & $\mathbf{2 0 1 5 - 2 0 1 9}$ & $\mathbf{2 0 2 0}$ \\
\hline Seasonally adjusted cases & 17 & 30 & 36 & 27 & 35 & 29 & 38 \\
Seasonally adjusted rates & 1.85 & 3.25 & 3.91 & 2.96 & 3.83 & 3.16 & 4.17 \\
RR & 2.28 & 1.29 & 1.07 & 1.42 & 1.09 & 1.33 & 1 \\
CI (95\%) & $(1.29-4.05) *$ & $(0.8-2.08)$ & $(0.68-1.69)$ & $(0.86-2.32)$ & $(0.69-1.72)$ & $(0.82-2.15)$ & \\
\hline
\end{tabular}

Note: RR is the risk ratio comparing the DBS of the four months of the year 2020 with those of each of the preceding 5 years and with the mean of those years. $\left.{ }^{*}\right)$ significant difference.

\subsection{Intra-Annual Analysis of DBS Comparing the Confinement and Postconfinement Periods}

Finally, Table 7 lists the results of the intra-annual analysis of the total DBS during the periods of March-June and July-October. This last analysis does not allow one to state that there is any significant change in DBS rates from the period of confinement to that of postconfinement in the year 2020. The variation observed in this year of the pandemic is quite similar to the variations found in comparing the periods of March-June vs. JulyOctober in 2017 and 2019 when there was no confinement, so the variation registered in 2020 could well be due to chance. 
Table 7. Intra-annual comparison of the confinement period months (March-June) with the postconfinement period months (July-October) for each year (seasonally adjusted data).

\begin{tabular}{cccccccc}
\hline Year & $\mathbf{2 0 1 5}$ & $\mathbf{2 0 1 6}$ & $\mathbf{2 0 1 7}$ & $\mathbf{2 0 1 8}$ & $\mathbf{2 0 1 9}$ & $\mathbf{2 0 1 5 - 2 0 1 9}$ & $\mathbf{2 0 2 0}$ \\
\hline Rates March-June & 2.76 & 4.16 & 3.11 & 2.91 & 3.25 & 3.24 & 3.04 \\
Rates July-October & 1.85 & 3.25 & 3.91 & 2.96 & 3.83 & 3.16 & 4.17 \\
RR & 1.53 & 1.3 & 0.81 & 1 & 0.86 & 1.03 & 0.74 \\
CI (95\%) & $(0.83-2.82)$ & $(0.81-2.09)$ & $(0.49-1.31)$ & $(0.59-1.70)$ & $(0.53-1.40)$ & $(0.62-1.72)$ & $(0.45-1.20)$ \\
\hline
\end{tabular}

Note: RR is the risk ratio comparing in each year the DBS of the confinement months with that of the postconfinement months.

\section{Discussion}

This study aimed at exploring the possible impact of the confinement measures imposed during COVID-19 on the incidence of deaths by suicide in the Extremadura region. Given the antecedents of observations in previous crises on their consequences for people's mental health and the increase in suicides [4-8,10-12], a similar impact could be expected during the course of the COVID-19 pandemic. Some studies have already shown the negative consequences of this crisis on mental health [2,3,27-29], but there as yet seems to be no evidence for any increase in DBS during the confinement period-rather there seems to be stability [32-34] or a decline [35-40] — and there are still insufficient data to indicate otherwise. Nonetheless, the possible immediate impact in the months following confinement and the general medium and long term impacts remain to be explored in greater depth. At the moment, some data already indicate that the feared increase in DBS could well occur [35].

Based on this work, it cannot be affirmed that there has been a significant change in the trend of DBS in the region of Extremadura during either the confinement period of 2020 or in the months following confinement. There could be some unidentified factor, apart from the exceptional situation of confinement, underlying the variations observed in the incidence rates because it was impossible to carry out an exhaustive analysis of the potential differentiating variables present in the year 2020 relative to the other years that might have provided some tentative explanation. Specifically, for many cases of DBS in the 2015-2018 period, there was no information available on sociodemographic (age, marital status, etc.), socioeconomic (employment situation), and personal (physical or mental health status, divorce rates, etc.) variables. Hence, the significant difference in DBS for the months of July-October between the years 2020 and 2015 can neither be attributed to chance nor be explained on the basis of the available data.

The incidence for the entire March to June period stayed fairly stable relative to the years preceding the crisis $(\mathrm{RR}=0.94 ; \mathrm{CI}$ : 0.56-1.58). Such a finding is coherent with those of other studies on the incidence of DBS during the first months of the pandemic [32-34], especially with the Massachusetts (RR $=0.94 ; C I$ : 0.76-1.15) [32] and the Queensland (RR = 0.94, CI: 0.82-1.06) [33] studies.

With regard to the rates of DBS observed in the months of July to October, these differences are not coherent with the results reported for Japan (RR = 1.16; CI: 1.11-1.21) [35], in which there was a significant $16 \%$ increase. In our analysis for the Extremadura region, the risk ratios for the years 2017 and 2019 were similar to that of 2020 for these same months, so that one cannot rule out that the variation observed was due to chance.

There are various possible mediating factors underlying these results. The government of Spain approved exceptional economic measures to mitigate the impact of COVID-19. These included actions aimed at strengthening the health sector, protecting families' welfare, helping employees and self-employed whose incomes had fallen, and supporting firms in terms of liquidity and flexibility so as to minimize unemployment. At the psychoemotional level, the social cohesion at individual, family, and community scales generated by the confinement situation could have acted as a protective factor for mental health [16], especially against suicidal behavior $[19,21]$, by contributing a feeling of security and connection. In addition, the confinement measure may have led to a situation that limited access to lethal means for persons with suicidal ideation or intentions. Given the published data on suicidal 
ideation at the start of the pandemic [44], this period could have been one of the incubation of active suicidal ideas, which would ultimately be consummated postconfinement.

Faced with the possible future scenario in which the increases in DBS that occurred in periods subsequent to the immediate stressor could be replicated in other crises, psychosocial interventions for the population at risk could prevent postcrisis complications, reduce mental disorders, improve mental health, and augment these persons' disaster resilience [45]. To this end, it is important to recognize the need for mechanisms with which to detect persons at risk of suicide during the postconfinement and postcrisis periods.

Finally, following the recommendations of the WHO [46], in order to implement preventive programs that stop or reduce such suicidal behaviors, as for example, the existing plans of prevention of Spain's various Autonomous Communities [47-49], it would be necessary to monitor the epidemiological trends of suicide in specific geographic areas through studies that help determine which population groups are at greatest risk, as some affected groups (such as women, adolescents, the elderly, or people with depression and post-traumatic stress disorder) suffer more and are more vulnerable to disasters [45]. The aforecited reference studies [32-40] respond implicitly to the need for this type of research at a local level, and their findings will be of relevance for the design of suicide prevention strategies in their specific zones of study. In this sense, a comparative analysis of the DBS registered by the IMLyCFs of Spain's various Autonomous Communities would show whether the results of this present study done at a local level are generalizable nationally. A thorough analysis of the cases that occurred during the confinement period by means of psychological autopsies $[50,51]$ would complement and enrich research in this area. It would help understand the personal circumstances surrounding the persons who have committed suicide, and thus make it possible to identify possible common risk factors, for example, mental health problems, the situation of social isolation, the feeling or perception of loneliness, and the reduced access to medical attention in persons undergoing medical or psychological treatment [11-13].

\section{Study Limitations}

This research has some limitations. Firstly, the incidence rates calculated from the cases registered in our data source might well increase in the coming months. The cases included in this study that occurred during the confinement and postconfinement periods of 2020 were those unequivocally classified as DBS. However, some deaths currently classified as being of unknown cause might come to be reclassified as DBS. Secondly, as the case frequency is low throughout the series, a variation of just one or two cases translates into a large percentage variation. Thirdly, our study was carried out in a single Spanish region with particular population, sociodemographic, and socioeconomic characteristics. This makes it difficult to generalize the results on a national or international level. Another limitation is that the RR is a measure of the effect that indicates whether the incidence of a phenomenon varies under certain circumstances; in this case, the confinement period, but this measure does not determine causality. We consider that to determine causality during COVID-19 confinement to the possible variation of DBS, it would be necessary to know the specific circumstances of each DBS that occurred throughout the study period 2015-2020, something hardly possible with the data that are usually collected by official sources. For this reason, we recommend a psychological autopsy as the proper methodology to know the particular circumstances of each person who committed suicide.

\section{Conclusions}

The pandemic situation of COVID-19 during 2020 has supposed a major socioeconomic and sanitary impact which determined that the researches about the consequences have progressed at astonishing speed, although there are many aspects which still remain unexplored in order to combat the consequences. In this sense, the present study opens an interest in possible measures of prevention and public health, although we cannot claim that there has been a significant change in the tendency of DBS in the region of Extremadura 
during the confinement period of 2020 ( $R R=0.94$; CI: 0.56-1.55), or in the months following confinement $(R R=1.33 ; C I: 0.82-2.15)$. Neither did any differences seen in the intra-annual analysis from the period of confinement to postconfinement reach statistical significance $(\mathrm{RR}=0.74 ; \mathrm{CI}: 0.45-1.20)$. However, in view of the antecedents observed in previous crises and their consequences for people's mental health as well as the increase in suicides, a similar impact could be expected during the COVID-19 pandemic. In this sense, it would be necessary to strengthen vigilance during and after the crisis and assure that assistance mechanisms are in place to prevent an increase in suicides.

Author Contributions: Conceptualization, I.P.-A.; methodology, I.P.-A.; formal analysis, I.P.-A.; investigation, I.P.-A.; writing—original draft preparation, I.P.-A.; writing—review and editing, I.P.-A., I.C.-G., and G.M.-M.P.; supervision, I.C.-G. and G.M.-M.P. All authors have read and agreed to the published version of the manuscript.

Funding: This study was carried out with funding from the European Social Fund through aid for the financing of predoctoral contracts for the training of Doctors in public R\&D centers belonging to the Extremadura System of Science, Technology and Innovation, in the fiscal year 2018, with the case file PD-18039.

Institutional Review Board Statement: Not applicable.

Informed Consent Statement: Not applicable.

Data Availability Statement: Data is contained within the article.

Conflicts of Interest: The authors declare no conflict of interest.

\section{References}

1. World Health Organization. Executive Board, 124. 2009. Commission on the Social Determinants of Health: Report by the Secretariat. Available online: https:/ / apps.who.int/iris/handle/10665/2110 (accessed on 6 January 2021).

2. Solomou, I.; Constantinidou, F. Prevalence and Predictors of Anxiety and Depression Symptoms during the COVID-19 Pandemic and Compliance with Precautionary Measures: Age and Sex Matter. Int. J. Environ. Res. Public Health 2020, 17, 4924. [CrossRef]

3. Gualano, M.R.; Lo Moro, G.; Voglino, G.; Bert, F.; Siliquini, R. Effects of Covid-19 Lockdown on Mental Health and Sleep Disturbances in Italy. Int. J. Environ. Res. Public Health 2020, 17, 4779. [CrossRef]

4. Bartoll, X.; Palència, L.; Malmusi, D.; Suhrcke, M.; Borrell, C. The evolution of mental health in Spain during the economic crisis. Eur. J. Public Health 2014, 24, 415-418. [CrossRef]

5. Cairns, J.-M.; Graham, E.; Bambra, C. Area-level socioeconomic disadvantage and suicidal behaviour in Europe: A systematic review. Soc. Sci. Med. 2017, 192, 102-111. [CrossRef]

6. Gili, M.; Roca, M.; Basu, S.; McKee, M.; Stuckler, D. The mental health risks of economic crisis in Spain: Evidence from primary care centres, 2006 and 2010. Eur. J. Public Health 2013, 23, 103-108. [CrossRef] [PubMed]

7. Haw, C.; Hawton, K.; Gunnell, D.; Platt, S. Economic recession and suicidal behaviour: Possible mechanisms and ameliorating factors. Int. J. Soc. Psychiatry 2015, 61, 73-81. [CrossRef]

8. Milner, A.; Page, A.; La Montagne, A.D. Long-term unemployment and suicide: A systematic review and meta-analysis. PLoS ONE 2013, 8, e51333. [CrossRef]

9. Kõlves, K.; Kõlves, K.E.; De Leo, D. Natural disasters and suicidal behaviours: A systematic literature review. J. Affect. Disord. 2013, 146, 1-14. [CrossRef] [PubMed]

10. Chang, S.; Stuckler, D.; Yip, P.; Gunnell, D. Impact of 2008 global economic crisis on suicide: Time trend study in 54 countries. BMJ 2013, 347, f5239. [CrossRef] [PubMed]

11. Córdoba-Doña, J.A.; San Sebastián, M.; Escolar-Pujolar, A.; Martínez-Faure, J.E.; Gustafsson, P.E. Economic crisis and suicidal behaviour: The role of unemployment, sex and age in Andalusia, southern Spain. Int. J. Equity Health 2014, 13, 55. [CrossRef]

12. López, J.A.; Gasparrini, A.; Artundo, C.M.; McKee, M. The effect of the late 2000s financial crisis on suicides in Spain: An interrupted time-series analysis. Eur. J. Public Health 2013, 23, 732-736. [CrossRef] [PubMed]

13. Chan, S.M.; Chiu, F.K.; Lam, C.W.; Leung, P.Y.; Conwell, Y. Elderly suicide and the 2003 SARS epidemic in Hong Kong. Int. J. Geriatr. Psychiatry 2006, 21, 113-118. [CrossRef]

14. Cheung, Y.T.; Chau, P.H.; Yip, P.S. A revisit on older adults suicides and Severe Acute Respiratory Syndrome (SARS) epidemic in Hong Kong. Int. J. Geriatr. Psychiatry 2008, 23, 1231-1238. [CrossRef]

15. Yip, P.S.; Cheung, Y.T.; Chau, P.H.; Law, Y.W. The impact of epidemic outbreak: The case of severe acute respiratory syndrome (SARS) and suicide among older adults in Hong Kong. Crisis 2010, 31, 86-92. [CrossRef]

16. Honjo, K.; Tani, Y.; Saito, M.; Sasaki, Y.; Kondo, K.; Kawachi, I.; Naoki, K. Living alone or with others and depressive symptoms and effect modification by residential social cohesion among older adults in Japan: The JAGES longitudinal study. J. Epidemiol. 2018, 28, 315-322. [CrossRef] 
17. Beutel, M.E.; Klein, E.M.; Brähler, E.; Reiner, I.; Jünger, C.; Michal, M.; Wiltink, J.; Wild, P.S.; Münzel, T.; Lackner, K.J.; et al. Loneliness in the general population: Prevalence, determinants and relations to mental health. BMC Psychiatry 2017, 17, 97. [CrossRef] [PubMed]

18. Calati, R.; Ferrari, C.; Brittner, M.; Oasi, O.; Olié, E.; Carvalho, A.F.; Courtet, P. Suicidal thoughts and behaviors and social isolation: A narrative review of the literature. J. Affect. Disord. 2019, 245, 653-667. [CrossRef] [PubMed]

19. Klonsky, E.D.; May, A.M.; Saffer, B.Y. Suicide, Suicide Attempts, and Suicidal Ideation. Annu. Rev. Clin. Psychol. 2016, 12, 307-330. [CrossRef] [PubMed]

20. Rugo, K.F.; Leifker, F.R.; Drake-Brooks, M.M.; Snell, M.B.; Bryan, C.J.; Bryan, A.O. Unit Cohesion and Social Support as Protective Factors Against Suicide Risk and Depression Among National Guard Service Members. J. Soc. Clin. Psychol. 2020, 39, $214-228$. [CrossRef]

21. Van Orden, K.A.; Witte, T.K.; Cukrowicz, K.C.; Braithwaite, S.R.; Selby, E.A.; Joiner, T.E. The interpersonal theory of suicide. Psychol. Rev. 2010, 117, 575-600. [CrossRef]

22. Bennardi, M.; Caballero, F.F.; Miret, M.; Ayuso-Mateos, J.L.; Haro, J.M.; Lara, E.; Arensman, E.; Cabello, M. Longitudinal Relationships Between Positive Affect, Loneliness, and Suicide Ideation: Age-Specific Factors in a General Population. Suicide Life Threat. Behav. 2019, 49, 90-103. [CrossRef]

23. World Health Organization. WHO Director-General's Opening Remarks at the Media Briefing on COVID-19-11 March 2020. Available online: https://www.who.int/es/director-general/speeches/detail/who-director-general-s-opening-remarks-at-themedia-briefing-on-covid-19---11-march-2020 (accessed on 6 January 2021).

24. Head of state. Royal Decree-Law $7 / 2020$, of March 12, by Which Urgent Measures Are Adopted to Respond to the Economic Impact of COVID-19. "BOE" no. 65, of March 13, 2020, p. 24996 to 25013. BOE-A-2020-3580. Available online: https: //www.boe.es/eli/es/rdl/2020/03/12/7 (accessed on 10 November 2020).

25. Ministry of the Presidency. Relations with the Courts and Democratic Memory. Royal Decree 463/2020, of March 14, which Declares the State of Alarm for the Management of the Health Crisis Situation Caused by COVID-19. "BOE" no. 67 of 03/14/2020. Sec. I. Page 25390. BOE-A-2020-5767. Available online: https:/ /www.boe.es/eli/es/rd/2020/03/14/463/con (accessed on 10 November 2020).

26. Ministry of the Presidency. Relations with the Courts and Democratic Memory. Royal Decree 555/2020, of June 5, which Extends the Sate of Alarm Declared by Royal Decree 463/2020, of March 14, which Declares the State of Alarm for the Management of the Situation of Health Crisis Caused by COVID-19. “BOE" no. 159 of 06/06/2020. Sec. I. Pages 38027 to 38036. Available online: https:/ / www.boe.es/eli/es/rd/2020/06/05/555 (accessed on 10 November 2020).

27. Balluerca, N.; Gómez, J.; Hidalgo, M.D.; Gorostiaga, A.; Espada, J.P.; Padilla, L.; Santed, M.A. The Psychological Consequences of COVID-19 and Confinement. Investigation Report; Publications Service of the University of the País Vasco: Biscay, Spain, 2020; Available online: https://www.ub.edu/web/ub/ca/menu_eines/noticies/docs/Consecuencias_psicologicas_COVID-19.pdf (accessed on 10 February 2021).

28. Orgilés, M.; Morales, A.; Delvecchio, E.; Mazzeschi, C.; Espada, J.P. Immediate Psychological Effects of the COVID-19 Quarantine in Youth From Italy and Spain. Front. Psychol. 2020, 11, 579038. [CrossRef] [PubMed]

29. Wang, C.; Pan, R.; Wan, X.; Tan, Y.; Xu, L.; Ho, C.S.; Ho, R.C. Immediate Psychological Responses and Associated Factors during the Initial Stage of the 2019 Coronavirus Disease (COVID-19) Epidemic among the General Population in China. Int. J. Environ. Res. Public Health 2020, 17, 1729. [CrossRef]

30. Brooks, S.K.; Webster, R.K.; Smith, L.E.; Woodland, L.; Wessely, S.; Greenberg, N.; Rubin, G.J. The psychological impact of quarantine and how to reduce it: Rapide review of the evidence. Lancet 2020, 395, 912-920. [CrossRef]

31. Carballo, J.J.; Llorente, C.; Kehrmann, L.; Flamarique, I.; Zuddas, A.; Purper-Ouakil, D.; Hoekstra, P.J.; Coghill, D.; Schulze, U.; Dittmann, R.W.; et al. STOP Consortium. Psychosocial risk factors for suicidality in children and adolescents. Eur. Child Adolesc. Psychiatry 2020, 29, 759-776. [CrossRef]

32. Faust, J.S.; Shah, S.B.; Du, C.; Li, S.X.; Lin, Z.; Krumholz, H.M. Suicide Deaths During the COVID-19 Stay-at-Home Advisory in Massachusetts, March to May 2020. JAMA Netw. Open 2021, 4, e2034273. [CrossRef]

33. Leske, S.; Kõlves, K.; Crompton, D.; Arensman, E.; De Leo, D. Real-time suicide mortality data from police reports in Queensland, Australia, during the COVID-19 pandemic: An interrupted time-series analysis. Lancet 2021, 8, 58-63. [CrossRef]

34. Radeloff, D.; Papsdorf, R.; Uhlig, K.; Vasilache, A.; Putnam, K.; Klitzing, K. Trends in suicide rates during the COVID-19 pandemic restrictions in a major German city. Epidemiol. Psychiatr. Sci. 2021, 30, 1-5. [CrossRef]

35. Tanaka, T.; Okamoto, S. Increase in suicide following an initial decline during the COVID-19 pandemic in Japan. Nat. Hum. Behav. 2021, 5, 229-238. [CrossRef] [PubMed]

36. Anzai, T.; Fukui, K.; Ito, T.; Ito, Y.; Takahashi, K. Excess Mortality From Suicide During the Early COVID-19 Pandemic Period in Japan: A Time-Series Modeling Before the Pandemic. J. Epidemiol. 2021, 31, 152-156. [CrossRef]

37. Qin, P.; Mehlum, L. National observation of death by suicide in the first 3 months under COVID-19 pandemic. Acta Psychiatr. Scand. 2021, 143, 92-93. [CrossRef]

38. Kim, A.M. The short-term impact of the COVID-19 outbreak on suicides in Korea. Psychiatry Res. 2021, 295, 113632. [CrossRef]

39. Deisenhammer, E.A.; Kemmler, G. Decreased suicide numbers during the first 6 months of the COVID-19 pandemic. Psychiatry Res. 2021, 295, 113623. [CrossRef] [PubMed] 
40. Calderon-Anyosa, R.J.C.; Kaufman, J.S. Impact of COVID-19 lockdown policy on homicide, suicide, and motor vehicle deaths in Peru. Prev. Med. 2021, 143, 106331. [CrossRef] [PubMed]

41. National Institute of Statistics. Continuous Register Statistics. Provisional data as of January 1, 2020. Autonomous Communities and Provinces. Available online: https:/ / www.ine.es/jaxi/Datos.htm?path=/t20/e245/p04/provi/10/\&file=0ccaa003.px (accessed on 10 November 2020).

42. Statistical Institute of Extremadura. Migration Statistics. Informative Note. Government of Extremadura. 2019. Available online: https: / / ciudadano.gobex.es/documents/9292336/10006092/MIGRACIONES2019.pdf/056a8c76-0385-4d6a-b91d-2ba1 24c668a7 (accessed on 10 November 2020).

43. Statistical Institute of Extremadura. Natural Movement of the Population. Informative note. Government of Extremadura. 2019. Available online: https: / ciudadano.gobex.es/documents/9292336/9762101/MNP2019D.pdf/b49ec498-7fe4-4421-a51b-a951 f27e24a0 (accessed on 10 November 2020).

44. Mortier, P.; Vilagut, G.; Ferrer, M.; Alayo, I.; Bruffaerts, R.; Cristóbal-Narváez, P.; Del Cura, J.; Domènech-Abella, J.; Felez-Nobrega, M.; Olaya, B.; et al. Thirty-Day Suicidal Thoughts and Behaviors in the Spanish Adult General Population during the First Wave of the Spain COVID-19 Pandemic. Epidemiol. Psychiatr. Sci. 2020, 1-25. [CrossRef]

45. Jafari, H.; Heidari, M.; Heidari, S.; Sayfouri, N. Risk Factors for Suicidal Behaviours after Natural Disasters: A Systematic Review. Malay. J. Med. Sci. 2020, 27, 20-33. [CrossRef]

46. Pan American Health Organization, World Health Organization Regional Office for the Americas. World Report on Violence and Health. 2003. Washington DC. Available online: https://www.who.int/violence_injury_prevention/violence/world_report/en/ summary_es.pdf (accessed on 12 January 2021).

47. Basque Government. Suicide Prevention Strategy in the Basque Country. Department of Health, Vitoria. 2019. Available online: https://www.euskadi.eus/contenidos/informacion/estrategia_prevencion_suicidio/es_def/adjuntos/plan_prevencion_ suicidio_cast.pdf (accessed on 12 April 2021).

48. Generalitat Valenciana. Council of Universal Health and Public Health. Valencia. 2018. Available online: http://www. prevenciodelsuicidi.san.gva.es / documents /7217942/7267322/GU\%C3\%8DA+SUICIDIO+\%C3\%81MBITO+SANITARIO.pdf (accessed on 12 April 2021).

49. Government of Castilla-La Mancha. Strategies for the Prevention of Suicide and Intervention Before Autolytic Behaviors in Castilla-La Mancha. Castilla-La Mancha Health Service. Toledo. 2018. Available online: https://sanidad.castillalamancha.es/ files/estrategias_para_la_prevencion_del_suicidio_ok.pdf (accessed on 12 April 2021).

50. Jiménez, J.; Arrufa, F.X.; Carrer, R.; Gay, M. Participation of the Institutes of Legal Medicine in suicide prevention programs: The case of Osona (Barcelona). Rev. Española Med. Leg. 2012, 38, 131-136. [CrossRef]

51. Martin-Fumadó, C.; Gómez-Durán, E.L. Suicide investigation: Psychological autopsy. Rev. Española Med. Leg. 2017, 43, 135-137. [CrossRef] 